\title{
Benchmarking road safety success: Issues to consider
}

Stephen Dann; Marie-Louise Fry

Australasian Marketing Journal; Nov 2009; 17, 4; ABI/INFORM Global pg. 226

\section{Benchmarking road safety success: Issues to consider}

\author{
Stephen Dann ${ }^{\mathrm{a}}$, Marie-Louise Fry ${ }^{\mathrm{b}, *}$ \\ "Australian National University, School of Management, Marketing and International Business. Canberra. ACT 0200. Australia \\ 'The University of Queenstand, UQ Business School, Ipswich, QLD 4305, Australia
}

\section{A R TICLE I N F O}

\section{Keywords:}

Social marketing

Road safety

Road safety success

Competitive benchmarks

Policy

\begin{abstract}
A B S T R ACT
Success in social marketing is rarely clear cut and even more rarely believed to have been achieved. Social marketing practitioners are under increasing scrutiny to benchmark efficiencies of social change programs to achieve 'success' outcomes. Using road safety as a case study, this paper addresses the complex nature of success within a social marketing context. First, we discuss the conundrum facing road safety in articulating 'success' when at policy level success is quantified objectively, yet at a community level perceptions of system failure are equated with individual death. Methodologically we apply comparative empirical approaches to examine perceptual versus objective road safety outcomes. The paper concludes with a discussion and proposal of alternate strategies for measuring programmatic success, and raise issues concerning the longevity of developing competitive and sustainable benchmarks

c) 2009 Australian and New Zealand Marketing Academy. All rights reserved.
\end{abstract}

\section{Introduction}

The growth of social marketing as a complement to alternate social change approaches has accelerated over the last two decades (Andreasen, 2006). Despite much discussion concerning social marketing's role, techniques and extension to the digital age (Andreasen, 2006; French and Blair-Stevens, 2006; Fry, 2007; Dann et al., 2007) there is surprisingly little examination of what constjtutes 'success' beyond a broad benchmark of increasing 'good' behaviour while 'decreasing' bad behaviour. In an era where performance outcome is critical to ongoing funding social marketing practitioners are increasingly under scrutiny to not only report campaign strategy but to evaluate and benchmark campaign outcomes as a measure of social change efficiency and effectiveness.

One such area that has a history of recording performance metrics is that of road safety. Road safety in Australia is unique in that despite recent adoption of social marketing as a strategy to combat risky driving behaviour, performance metrics in the form of fatality trend data have been recorded since 1925 (Peder et al., 2004). In spite of overwhelming indications that road safety strategy initiatives have achieved significant successes over past 35 years, road safety faces a continuing situation where definitive 'success' is rarely achieved, 'failure' is enduring and the perceptual outcome of road safety strategy is represented as a 'crisis' situation in mainstream media. This scenario represents a conundrum for road safety practitioners. In many ways, articulating success where mortality figures represent the outcome of behaviour emphasises the conflict road safety faces. The reality of personal tragedy pre-

\footnotetext{
"Corresponding author.

E-mail address: mi.fry@uq.edu.au (M.-L. Fry)
}

sents a perception of 'failure', while the objective statistical analysis of strategy implementation simultaneously suggests 'success' of that same campaign. As such, are road safety initiatives are able to benchmark and achieve successful outcomes? In answering this question, the paper is divided into three sections. The first section examines the relationship between objective and perceptual success paying particular attention to the key epistemological issue of whether 'success' is a possible outcome for road safety. The second section applies comparative empirical approaches to examine perceptual versus objective road safety outcomes. The paper concludes with a discussion and proposal for alternate measures of success.

\section{2. 'Success' in road safety}

Marsh and McConnell (2008) argue the nature of success is multifaceted and complex. They specify the evaluation of success outcomes must include consideration of three dimensions: the process (policy development), the program (interventions), and the political environment (media commentary). Inherently, what constitutes success differs according to the perspectives of key participants, observers and the policy process. While an evidencebased perspective provides an objective measure of success, in many ways the evaluation itself is socially constructed and politically articulated. Thus, any attempt to grapple with the nature of success must take into consideration the complexity and interrelationships between policy, program and the environment. In particular, the conundrum surrounding the articulation of success in road safety is exacerbated at all three levels of Marsh and McConnell's (2008) framework. It would seem that conceptualisation of 
success differs across these sectors of the road safety system, despite each sector individually aiming to benefit society in the long run.

At a policy level road safety is guided by the philosophy of Zero Tolerance which embodies the principle of preventable death. Zero Tolerance is driven by two ethical rules: 'Life and health can never by exchanged for other benefits within society' and 'Whenever someone is killed or seriously injured necessary steps must be taken to avoid a similar event' (Tingvall and Haworth, 1999). Implicit within the model is that road-related fatalities should not be accepted as inevitable, that priority is given to the preservation of human life, and that zero fatalities are not only possible but is an achievable outcome of strategy implementation (Smith, 2000). Within this model success is construed as zero deaths within the road system. While visionary, a discrepancy exists between the objective target of zero deaths and the capacity of the road system to absorb human error. Despite controlling for key factors that influence the probability of road fatalities eventuating (e.g., road infrastructure improvements, vehicle modifications, education and attitudinal factors) Zero Tolerance lacks consideration that a percentage of road deaths are attributed to compounding factors such as luck, poor mechanical conditions, random factors, environmental intervention and non-controllable circumstances that are beyond the control of the road system. Although due care is taken to create a safe road system there continues to remain a margin where road death and serious injuries cannot be prevented.

While Zero Tolerance offers an overarching philosophical perspective, the National Road Safety Strategy (NRSS) is the policy framework guiding road safety program implementation across State and Territories within Australia. At a program level, articulation of road safety success is construed objectively and is generally expressed in the number of collisions, casualties and fatalities that occur in the transport system. The NRSS aims to reduce the road fatality rate per 100,000 population by $40 \%$ by 2010 (Australian Transport Council, 2006). Specification of a target acknowledges an objective benchmark to evaluate the relationship between program implementation and performance. Yet, there is a conflict between the NRSS at the program level and the principle of Zero Tolerance at the policy level. Acceptance of a $40 \%$ objective benchmark acknowledges tolerance of a residual road toll within a system that aims for a zero road deaths. Although the idea of promoting a zero road toll appears to be supported in principle, the ability of Vision Zero to achieve its outcome is challenged by and is a challenge to current practice. At policy level the magnitude of this discrepancy has impact on the articulation of success within a road safety context. Despite the implicit underlying rhetoric of Zero Tolerance advocating a zero toll, there is discrepancy between the vision per se and the implementation of the vision through the NRSS framework.

Adjunct to the issue of aligning a visionary perspective with implementation strategy is the interaction between goal setting and measurement of performance efficiencies. Elementary performance metrics indicate setting targets is critical to benchmarking strategy against outcomes (Ambler, 2000). In road safety, the setting of attainable targets at the program level is especially crucial. Yet, the nature of road safety is that positive achievement in any number of successive years may be overshadowed by a single year where a target is not met. The precursor to the Queensland 'Enough is Enough' campaign was an increase in road fatalities of 311 in 2004 to 330 in 2005. Despite program implementation, Queensland road fatalities stood at 336 in 2006. The campaign was consequently abandoned for not meeting targets. Similarly, by August 2006 the projected NRSS fatality rate was targeted at 7.0 fatalities per 100,000 population. The actual rate was 7.9 per 100,000 (Australian Transport Council, 2006). While application of objective metrics to road safety enables evaluation of the relationship be- tween performance and intervention implementation, target setting requires translating return on investment into the compliance with behaviour, adherence to long-term behaviour change. as well as integration of individual failures amidst aggregated success. In an environment where the population of licensed drivers is increasing, and where road infrastructure, vehicle capacity for both safety and speed, and driver education and knowledge is improving, is there a limit to substantially reducing road fatalities? Or has road safety met, or almost met, its saturation point? Is road safety in maintenance mode where objective road toll statistics may not necessarily reduce but may, in actual fact, fluctuate? These questions are asked in hindsight of not achieving projected targets.

Marsh and McConnell (2008) identify the political environment as a third dimension influencing the conceptual nature of success. In particular, the media is cited as a key contributor influencing the perception of success at a community level. Marsh and McConnell (2008) argue that environmental impacts, such as the media, influence an individual's judgement as to whether road safety is in a state of 'success' or 'failure'. The concept of 'perceptual failure' is the subjective belief that an intervention program has failed to achieve an acceptable level of success due to the visibility of incidents of failure. Road safety is an invisible benefit, with road safety failure being a visible and visual spectacle. Consequently, road trauma has a clearer match with Tversky and Kahneman's (1982) heuristics of availability where the presence of a highly memorable event is more likely to be recalled than mundane information associated with the event, or the absence of the event. The single photograph of a wrecked car has the ability to portray the inevitable perception of failure in an emotive and powerful light. Thus, the framing of media reports and frequency of reports over time influences the ease of which recall of road safety success or failure can be bought to mind for estimation of the probability of that behaviour occurring. The framing of the media message as either a loss-frame (i.e., negative positioning) or a gain-frame (i.e., positive positioning) also influences judgements of failure/success and non-achievement/ achievement. Tversky and Kahneman (1982) suggest that the availability heuristic is effective not only through ease of recall or imagination, but also because remembered images are connected with affect. Thus, long-term portrayal of road safety in the media with vivid images and negative positioning cues biases probability judgements where perceptual failure wins against perceptual success.

The above analysis suggests the conceptualisation of success within road safety is problematic. Articulating success in road safety requires a balancing act between macro-level analysis of longitudinal objective-based statistics, consideration of the reality of personal tragedy at the micro-level, as well as communicating road safety effectiveness (i.e., perceptual success) in the media at a broader community/social level. Yet is road safety able to articulate overall program success despite the occurrence of failure at an individual level? The next section addresses this question putting forward two propositions as a means to verify relative levels of success (i.e., perceptual versus objective) of road safety campaigns

\section{Methodology}

A two part methodology was implemented to verify relative levels of success of road safety campaigns. Study 1 evaluates the perceptual success of road safety by analysing road safety media representation. Study 2 evaluates objective success by re-analysing road safety metrics taking into consideration population increases. The period of analysis from 1996 to 2007 was bounded by access to newspaper data for mapping media reporting of road safety outcomes, and provides a longitudinal snapshot of road safety intervention outcomes. 


\subsection{Study t: perceprual success}

Study 1 is a prima facie test of Tversky and Kahneman's (1982) heuristics of availability which states the presence. frequency of exposure and framing (loss versus gain) of road safety risk in the media is more likely to be recalled than mundane information or the absence of an event. As such. Proposition 1 argues that the availability heuristic (i.e., frequency and message frame) should influence road safety media coverage toward reporting the memorable against the reporting of successes.

Proposition 1 was examined by conducting a content analysis of road safety media coverage across Australian newspapers (national and regional) from 1996 to 2007 (see Table 1). Newspaper articles were sourced from the Factiva Archives using the search terms 'road safety', 'road trauma', 'road accidents', and 'road toll'. Analysis of the frequency of road safety coverage indicates significant increases in reporting over the period of analysis. In 1996, 32 articles reported on road safety issues. In the four year period to 2000 frequency increased by $600 \%$ to a total of 191 articles. By 2007, newspaper road safety commentary had increased by a further $232 \%$ to a total of 445 articles. In relative terms, the impact of the substantial increases in the reporting of road safety issues in Australian newspapers rose on average from 2.6 articles per month in 1996, to 1.2 articles per day in 2007.

Further analysis was undertaken to evaluate the portrayal of road safety as either a gain- or loss-framed message. Despite the substantial increase in media coverage of road safety issues, the percentage of newspaper articles reporting road safety as a gainframe decreased from $16 \%$ in 1996 to $1 \%$ in 2007. Gain-framed reporting was replaced with loss-framed reporting. In 1996 positioning road safety as a loss-frame represented $84 \%$ of all road safety articles, increasing to $99 \%$ in 2007 . Recurrent 'loss-based' themes and corresponding headline captions include: graphically intense responses (horror/carnage), death proclamations (killed/ fatalities/fatality/fatal; death/die/dead/statistics of deaths/convictions), victim blaming statements (reckless), quasi-sympathetic statements (tragic/tragedy), and repetition of road safety tag lines (bloody/stupid). Few articles evaluated longitudinal outcomes of road safety initiatives, with preference directed towards sensationalising individual trauma.

Interpreting the portrayal of road safety in the media in hindsight of the availability heuristic indicates that evoking and representing road safety with loss-frame adjectives such as negative, tragic, stupid and carnage builds a memorable perception of failure. In particular, failure suggesting road safety prevention initiatives are less than effective in stemming road trauma, which in turn indicates a system-wide crisis. This perception of failure is further reinforced by the frequency of media placement of these themes, and the message recipients' opportunity-to-view the loss-framed messages. In summary. Proposition 1 is upheld.

\subsection{Study 1: objective success}

Study 2 evaluates the objective success of Australian road safety initiatives taking a grounded quasi-proposition testing methodology. Despite the suggestion that there is a system-wide crisis in

Table 1

Australian road safety media coverage

\begin{tabular}{llll}
\hline Year & $\begin{array}{l}\text { Gain-framed } \\
\#(\%)\end{array}$ & $\begin{array}{l}\text { Loss-framed } \\
\#(\%)\end{array}$ & $\begin{array}{l}\text { Total articles } \\
\#\end{array}$ \\
\hline 1996 & $5(16)$ & $27(84)$ & 32 \\
2000 & $5(3)$ & $186(97)$ & 191 \\
2007 & $3(1)$ & $441(99)$ & 445 \\
\hline
\end{tabular}

stemming road trauma, Proposition 2 argues that road safety initiatives are succeeding in stemming road trauma yet need to consider long-term objective statistics as opposed to taking a short-term perspective. To test this proposition, Study 2 first reviews road safety trend data from 1925 to 2007.

At the commencement of reporting road death statistics in 1925 there were 700 road deaths, representing 12 deaths per 100,000 population (FORS, 1998). With notable exceptions of the $1920 \mathrm{~s}$ Depression and World War II fatality rates steadily rose to a peak death rate in 1970 of 3798 fatalities representing 30.4 deaths per 100,000 population (FORS, 1998). Following the 1970 peak, the greatest decline in road fatalities occurred with a low end peak in 2000 where the fatality rate dropped to 8.8 deaths per 100,000 population (ATSB, 2004). Although less pronounced than the previous period the downward trend for road deaths has continued at an annual average decrease of $1.7 \%$ from 2002 to 2006 (ATSB, 2007). This brief overview of historical road safety trend data clearly indicates considerable declines in road-related death.

Nonetheless, a limitation of the current road fatality metric is a lack of adjustment of road fatality performance based on population size, and the relative increase or decrease in the population. As a consequence current examinations of annual road safety performance statistics are not measured against the same set of benchmarks. Thus Proposition 2a tests whether inclusion of an adjusted per capita death rate taking into consideration variation in population over time will obtain objective success.

To test Proposition 2a an Adjusted Death Rate (ADR) figure is calculated for each state and the national total by dividing the road toll figure by the state population (see Table 2). Scores are then converted from the fractional decimal percentages into an ADR measure. Population data is based on the Australian Bureau of Statistics 'Australia at a Glance' series with the annual road fatality statistics obtained from the Australian Transport Safety Bureau 'Road Fatality Statistics' database. Whilst other road safety measures are calculated in death per 100,000 population head, the initial ADR calculation uses the unmodified state population figures from the Australian Bureau of Statistics data. As the purpose of the calculation is to create an annually adjusted rate per head of population, measuring population units in 100,000 or 1000 blocks does not influence the final ADR figure.

Review of the ADR scores in Table 2 indicates an overall pattern of decline in the loss of life on Australian roads over the past decade, despite variability across some states. States showing a continuing gradual decline in road fatalities between 1996 and 2006 include: New South Wales, Victoria, Queensland and South Australia. Comparing 2006 ADR figures with ADR of the previous two years shows Tasmania and Northern Territory have fluctuated in their road safety metric. Western Australia's score for 2006 was higher than previous years. Tasmania showed a significantly higher ADR for 2005, with a reduction in 2006 which was somewhat higher than the 2004 ADR.

Across the board, there has been a continual decline in road deaths, and an arguable case for claiming successful interventions on aggregate scores, lives saved and declining rates of road accidents against steadily growing state and national population totals. This is further illustrated in Fig. 1 with a graphical representation of the progression of the national population, road toll and ADR.

\section{Discussion}

Road safety prevention is an inherently complex issue. This paper aimed to elucidate the complexities associated with articulating success within a road safety context by asking: Can road safety interventions achieve successful outcomes? The answer simply is in the affirmative. Nonetheless, there is particular 
Table 2

State populacion, road death and adjusted death tating.

\begin{tabular}{|c|c|c|c|c|c|c|c|c|c|c|c|}
\hline & 1996 & 1997 & 1998 & 1999 & 2000 & 2001 & 2002 & 2003 & 2004 & 2005 & 2006 \\
\hline NSW popn & 6115 & 6190 & 6204 & 6274 & 6342 & 6412 & 6464 & 6609 & 6640 & 6682 & 6731 \\
\hline Roadtoll & 581 & 576 & 556 & 577 & 603 & 524 & 561 & 539 & 510 & 508 & 499 \\
\hline ADR score & 95 & 93 & 90 & 92 & 95 & 82 & 87 & 82 & 77 & 76 & 74 \\
\hline VIC popn & 4502 & 4541 & 4561 & 4605 & 4661 & 4712 & 4766 & 4823 & 4873 & 4911 & 4973 \\
\hline Roadtoll & 417 & 377 & 390 & 383 & 407 & 444 & 397 & 330 & 343 & 346 & 337 \\
\hline ADR score & 93 & 83 & 86 & 83 & 87 & 94 & 83 & 68 & 70 & 70 & 68 \\
\hline QLD popn & 3277 & 3355 & 3339 & 3401 & 3456 & 3512 & 3566 & 3635 & 3707 & 3801 & 3882 \\
\hline Roadtoll & 385 & 360 & 279 & 314 & 317 & 324 & 322 & 310 & 311 & 330 & 336 \\
\hline ADR score & 117 & 107 & 84 & 92 & 92 & 92 & 90 & 85 & 84 & 87 & 87 \\
\hline SA popn & 1474 & 1479 & 1474 & 1480 & 1487 & 1493 & 1498 & 1515 & 1520 & 1526 & 1534 \\
\hline Roadtoil & 181 & 148 & 168 & 151 & 166 & 153 & 154 & 157 & 139 & 148 & 117 \\
\hline ADR score & 123 & 100 & 114 & 102 & 112 & 102 & 103 & 104 & 91 & 97 & 76 \\
\hline WA popn & 1732 & 1763 & 1766 & 1798 & 1831 & 1861 & 1884 & 1906 & 1927 & 1950 & 1982 \\
\hline Roadtoll & 247 & 197 & 223 & 218 & 212 & 165 & 179 & 180 & 178 & 163 & 203 \\
\hline ADR score & 143 & 112 & 126 & 121 & 116 & 89 & 95 & 94 & 92 & 84 & 102 \\
\hline TAS popn & 473 & 473 & 475 & 474 & 472 & 470 & 470 & 473 & 473 & 477 & 482 \\
\hline Roadtoll & 64 & 32 & 48 & 53 & 43 & 61 & 37 & 41 & 58 & 51 & 54 \\
\hline ADR score & 135 & 68 & 101 & 112 & 91 & 130 & 79 & 87 & 123 & 107 & 112 \\
\hline NT popn & 174 & 178 & 182 & 187 & 190 & 193 & 196 & 200 & 198 & 199 & 200 \\
\hline Roadtoll & 72 & 60 & 69 & 49 & 51 & 50 & 55 & 53 & 35 & 55 & 42 \\
\hline ADR score & 414 & 337 & 379 & 262 & 268 & 259 & 281 & 265 & 177 & 276 & 210 \\
\hline ACT popn & 304 & 308 & 308 & 310 & 308 & 310 & 311 & 322 & 322 & 323 & 324 \\
\hline Roadtoll & 23 & 17 & 22 & 19 & 18 & 16 & 10 & 11 & 9 & 26 & 13 \\
\hline ADR score & 76 & 55 & 71 & 61 & 58 & 52 & 32 & 34 & 28 & 80 & 40 \\
\hline Aust total popn & 18,054 & 18,289 & 18.311 & 18.532 & 18,750 & 18.967 & 19,157 & 19,485 & 19,663 & 19,872 & 20,111 \\
\hline Roadtoll & 1970 & 1767 & 1755 & 1764 & 1817 & 1737 & 1715 & 1621 & 1583 & 1627 & 1601 \\
\hline ADR score & 109 & 97 & 96 & 95 & 97 & 92 & 90 & 83 & 81 & 82 & 80 \\
\hline
\end{tabular}

Estimated resident population data represented in 1000 units as per the source ABS figures.

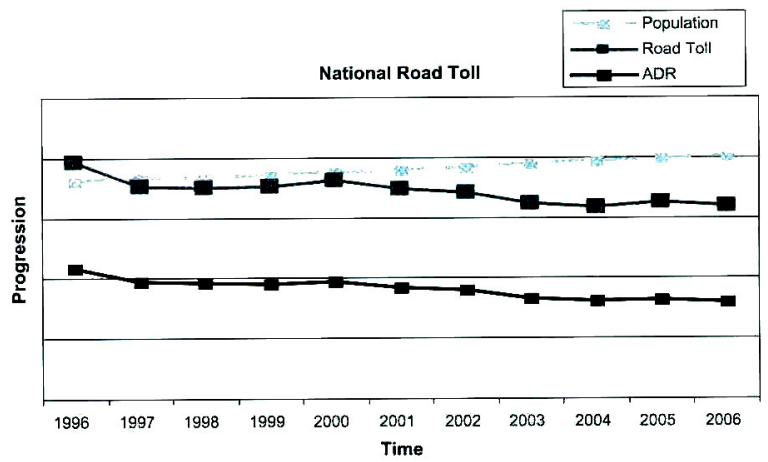

Fig. 1. Road toll and population growth over time.

concern regarding the inverse relationship between trend data and media coverage. On a range of measures, the total road safety intervention package of the road system, road user, social marketing. law enforcement and engineering is resulting in positive change and arguably successful outcomes. Fewer deaths are occurring despite rising rates of vehicle usage and rising population levels. How then can the negative media coverage be reconciled with the positive statistical results?

To answer the question of road safety success it is necessary to revisit the Marsh and McConnell's (2008) conceptualisation of suc- cess within policy development framework. Marsh and Mcconnell argue that in order to evaluate the effectiveness of policy implementation evaluative metrics need to produce objective and relative measures of success. They put forward a framework for assessing success focusing on three dimensions: process success, program success and political success. The dimensions of success of concern to this discussion are program and political success. An adaptation of Marsh and Mcconnell's (2008) program success is applied further develop benchmarking measures for determining 'success' in road safety and as an exploration of how 'success' can 
be determined in related types of social marketing campaigns. We interpret political success in terms of the propensity of the media to influence society's perception of road safety achievements.

\subsection{Program benchmark metrics: road safety success measured in statistical outcomes}

The accepted road safety metric to quantify objective success of road safery efforts is expressed by the number of collisions, casualties and fatalities that occur within the transport system (Peder et al., 2004). Typically, fatality rates are recorded as rate of death per chosen measure (e.g., deaths per 100,000 population). These measures are currently used as retrospective metrics and historical trend data. Rather than using retrospective data, it is proposed that road fatality rates be used as the foundation for the development of a competitive benchmark of "Projected Death Rate", Projected Death Rates combines the Adjusted Death Rate measurement of the previous year with the projected population levels for the forthcoming period. This creates a social marketing competitive benchmark in line with the recommendations of Ambler (2000) and Uncles (2005) for commercial marketing. Competitive benchmarking sets realistic goals which are adjusted for changes in markets such as market expansion or growth in the overall size of the market. For road safety campaigns, population growth, vehicle movement, and vehicle registrations provide a set of metrics for overall target populations to be addressed by road safety interventions. Projected Death Rate (PDR) figures set a target road toll based on the current National Average Adjusted Death Rate (national total) or state based Adjusted Death Totals. For the purpose the paper, only the National Projected Death Rate is calculated for years 2008-2012. These figures are outlined in Table 3, and explained in further detail below.

The formulae for the Projected Death Rate is based on multiplying an existing Adjusted Death Rate measure with the ABS projected population for a given year. To illustrate the ADR concept four different calculations were created based on the different formats of Adjusted Death Rates. The first projected road toll (Series 1 ) is a mathematical projection of road death based on the maintenance of the current (2007) National ADR, and no incremental improvement in the ADR figures. The flat rate assumes any significant performance improvements in one state would be counter balanced by losses in other areas to leave the road safety outcomes static across the entire country.

The second projected road toll is based on an assumption of continual incremental success in road safety which lowers the $\mathrm{Na}$ tional ADR by 1 point each year (e.g., 2008 has an ADR of 80, 2009 uses an ADR of 79). This approach recognises the continued learning capacity of the road safety intervention campaigns, and the capacity for better performance whilst also compensating for population growth rates.

The third form of projected road toll (Series 3 ) is designed to project the lower limit of the best case road toll based on the current lowest ADR across the past decade of ADR calculations which, in this case, is represented by the 2006 Victorian road toll
(ADR68). The best case scenario calculation is aimed at providing a minimum expected fatality rate for the national toll assuming that all states and territories equal the all time best recorded ADR from the sample period. This is a mathematical calculation to provide a lower boundary for assessing road safety success.

The fourth form of the Projected Death Rate (Series 4) operates in reverse to Series 3 projections as it attempts to determine the upper boundary worst case scenario of fatalities. This projection calculated the projected death rate for the nation based on the highest aggregate ADR score from the sample time frame (ADR109) which occurred in 1996. Initial calculations of the upper boundary using the highest state figures resulted in an ADR score of 414 from the 1996 Northern Territory ( 72 death per 174,000 residents). This was regarded as an improbable upper theoretical limit based on the size of the NT sample. Consequently, although the best case was drawn from the state levels, the worst case uses the national aggregate figures.

If the ADR projection rates are used to calculate target rates for the road safety program success rates, it becomes possible to set best case scenarios for annual road fatalities, and realistic goals based on different scenario plans. For example, the current best case (ADR68) would result in approximately 1400 deaths, and the maintaining the current best case national performance (ADR80) would project a total of approximately 1650 deaths for the 2008 period. This form of programmatic goals can then be measured using the actual fatality rates of the period against the population adjusted predicted rates of death.

However, whilst these benchmarks are based on an unemotional application of mathematics, economics and statistical data, road safety is not a value neutral position. As a society, there is a need to open discussion as to when 'enough' becomes 'enough' in seeking to prevent death in one aspect of societal interaction, and the allocation of resources that can be diverted to other areas of the community.

\subsection{Political benchmark metrics: road safety success measured in media outcomes}

Whilst the programmatic goals can be set in terms of projected deaths per annum, road safety is also a political outcome, and as such, is dependent on less objective outcome measurements. As noted in the media coverage study, the nature and volume of negative road safety outcomes has increased in inverse proportion to the positive decline in ADR road fatality. Road safety, as with many social marketing campaigns, can only offer uncertain outcomes from positive or negative behaviour. Speeding is not automatically fatal, and safe driving behaviour is not automatically rewarded with survival. Road safety success is partly a matter of perception within the target audience and community. Potentially, declarations of success within road safety may encourage a decline in attention to safety messages, or a decrease in adherence to road safety conditions. Alternatively, positive reinforcement and perceptions of tangible outcomes from intangible behaviour may increase adherence to road safety messages. Currently, as

Table 3

Projected Ausiralian road safety benchmarks.

\begin{tabular}{|c|c|c|c|c|c|}
\hline & 2008 & 2009 & 2010 & 2011 & 2012 \\
\hline Projected aational population & $20,677,500$ & $20,820,100$ & $20,956,600$ & $21,086,800$ & 21.212 .700 \\
\hline Series 1: Aggregate ADR (annual declining) & 1654 & 1645 & 1635 & 1624 & 1612 \\
\hline Series 2: ADR flat progression (ADR80) & 1654 & 1666 & 1677 & 1687 & 1697 \\
\hline Series 3: ADR best case (ADR68) & 1406 & 1416 & 1425 & 1434 & 1442 \\
\hline Series 4: ADR worst case (ADR109) & 2254 & 2269 & 2284 & 2298 & 2312 \\
\hline
\end{tabular}

" Based on Series C Population estimates for ABS (2002) Population Projections Australia 2002-2101 ABS3222.0. Series C estimates the lowest population growth to produce the most conservative estimate of population size for the formula. 
contemporary media coverage emphasises failure at the individual level and macro-level, the outcomes associated with positive portrayals of road safety success are relatively unknown.

Future research is needed to determine public opinion as to what constitutes 'success' within social marketing, and more specifically within the road safety framework. The question of whether the community is prepared to accept a trade-off of a minimum level of unavoidable fatalities in exchange for road vehicle movements at the current, or increased levels, needs to be further explored.

\section{Future direction and implications for social marketing management}

This paper has opened a metaphorical can of worms by suggesting that success in road safety interventions results in an annual projected death rate of over 1400 people. It must be noted that the authors are approaching the annual road toll from a perspective of death minimization based on incremental improvement in all aspects of road safety interventions. However, as social marketers, the authors are unwilling to accept a zero tolerance benchmark as a credible outcome for an intervention that depends on human behaviour, road and vehicle engineering, weather conditions, traffic movements and the occasional element of misfortune. From a social marketing perspective, road safety interventions have a range of human controllable elements that can be influenced, and system-wide 'upstream' factors that can be adjusted through engineering. law or other approaches. There is no capacity within a social marketing road safety intervention to force compliance, or to realistically expect a zero death outcome from a complex interaction of human and environment factors.

Second, as noted in the statistics above, successful road safety interventions still result in the deaths of over a 1400 people in road trauma each year. However, on review of the Predicted Death Rates (Table 2), the success of road safety can be seen in the gap between the ongoing projected worst case scenario (1996 level fatality) and the recent success of 2006 and 2007 . Whilst 1600 deaths can be seen as a road crisis by the media who focus on individual incidents, without these interventions, at least a further 600 people would die per annum. Although the media message in 1996 was the most positive coverage of the entire study, the ADR calculation indicates this was the worst year for road death per head of population. Consequently, it is important for the road safety interventions to be based on programmatic rather than political metrics - implementing a crisis style reaction based on media commentary will not match the reality of the incremental and ongoing success of the current interventions.

The gap between the political success and the programmatic success is a key area for social marketers to learn from the road safety intervention scenario. As Marsh and McConnell (2008) highlighted, success is a negotiated outcome - for family and friends of the deceased, one road trauma death is the micro-level failure of the road safety system. For the social marketer, one death is a part of the macro-level intervention framework where success is based on less total deaths than the previous measurement period. Social marketers are faced with the need to set acceptable loss rate whilst they continue developing micro-level interventions to produce sustained incremental improvements given the current success rate in a range of road safety activities exceeds $99.9 \%$ when measured through RBT, drug tests or deaths per head of population.

This leads to the final problem for road safety social marketing the road safety interventions function at the macro-level with upstream intervention, legal, education, engineering and social marketing campaigns engaging in a range of system level changes to improve the road safety environment. Although road trauma campaigns function at the macro-level, road safety incidents occur at the micro-level. Social marketers need to accept that aggregate success at the macro-level will occur despite individual micro-level system events. Moving forward with a campaign strategy has to be based on the programmatic success which is a reflection of the reality in which the future campaigns will operate. Reinforcement strategies differ from new interventions, and basing a campaign on the perception of a system-wide failure can create ineffective future interventions. Accepting aggregate success is a key to developing appropriate interventions to assist future micro-level intervention successes.

\section{References}

ABS, 2002. Population Projectians Australia 2002 -2101. ABS3222.0.

Ambler, T., 2000. Marketing metrics. Business Strategy Review 11 (2), 59-66.

Andreasen, A., 2006. Social Marketing in the 21st Century. Sage Publications. Thousand Oaks, California.

ATSB, 2004. Road Safety in Australia: A publication commemorating World Health Day 2004. Australian Transport Safety Bureau.

ATSB, 2007. Road Deaths Australia 2006 Statistical Summary. Australian Transport Safety Burreau, ACT Australia. \&http://www.atsb.gov.au/publications/2007/pdf/ murf 2006.pdf (accessed 20.01.08.).

Australian Transport Council, 2006. The National Road Safety Action Plan 20072008.

Dann. S., Fry. M.L., Binney, W.. Sullivan-Mort, G., Harris. P.. 2007. Challenges facing social marketing. Journal of Public Affairs 7 (4), $291-304$.

FORS, 1998. The History of Road Fatalities in Australia. Monograph 23. Federa office of Road Safety.

French, J., Blair-Stevens, C., 2006. Social Marketing National Benchmark Criteria, National Social Marketing Centre, London, UK.

Fry, M.L., 2007. Looking through the social marketing lent: research issues and techniques Australasian Journal of Marker and Social Research 15 (2) 35-43.

Marsh, D. McConnell, 2008. Towards a framework for examining policy success. Australian Political Studies Association Conference. Brisbane. July.

Peder, M. Scurfield. R., Sleet. D., Mohan. D. Hyder, A.A., Jarawan, E., et al., 2004 World Report on Road Traffic Injury Prevention. No. ISBN: 924156260 9. World Health Organisation, Geneva Switzerland.

Smith, K. 2000. Road Safety: Past, Present and Future. Australias Institute of Traffic Planning and Management. Queensland, June.

Tingvall, C. Haworth, N., 1999. Vision Zero - An Ethical Approach to Safety and Mobility. in: 6th International Conference in Road Safety and Traffic Enforcernent: Beyond 2000, Melbourne.

Tversky, A., Kahneman, D., 1982. Availability: a heuristic for judging frequency and probability. In: Kahenman, D., Slovic, P., Tversky. A. (Eds.), Judgement Under Uncertainty: Heuristics and Biases. Cambridge University Press, Cambridge, pp $163-189$.

Uncles. M. 2005. Marketing metrics: a can of worms or the path to enlightenment? Joural of Brand Management $12(6), 412-418$. 